\section{Arthur Ferguson MacCallan: trachoma pioneer in Egypt 1903-1923}

\author{
Michael MacCallan
}

Arthur Ferguson MacCallan CBE, MD, FRCS (1872-1955) was an ophthalmic surgeon who undertook his pioneering work in Egypt between 1903 and 1923 (figure 1). ${ }^{\mathrm{i}} \mathrm{He}$ became a world authority on trachoma; the MacCallan Classification of Trachoma, initially published in 1908, was the first grading system used to standardise the diagnosis of trachoma and was later adopted by the WHO. He also established the ophthalmic hospital infrastructure consisting of travelling and permanent hospitals, along with the training of surgeons. This fight to eliminate trachoma continues, with the WHO setting a target date for the Global Elimination of Blinding Trachoma by 2020 ('GET 2020'). As a contribution to achieving this goal, the International Coalition for Trachoma Control (ICTC) inaugurated the 'ICTC MacCallan Medal'ii in 2014. By naming this award after Arthur, it recognises his pioneering spirit and accomplishments which continue to resonate with the profession today.

The seeds of Arthur's work were sown when the highly contagious eye-disease trachoma, which had existed in Egypt for centuries, was imposed on the Europeans due to the return of the British and other combatants' troops to their respective countries after Napoleon's invasion and subsequent defeat in Egypt (1798-1801). In Britain, this led to the opening, in 1805 , of the dispensary for Curing Diseases of the Eye and Ear ('Moorfields') to treat the disease. Britain's further involvement in Egypt increased from 1882 , to protect its interest in the Suez Canal, but it was not until the late 1890s, during the construction of the first Aswan Dam, that the financier and philanthropist

iSource: Light out of Deep Darkness: A biography of Arthur Ferguson MacCallan by Michael MacCallan, privately published in 2013.

ii This award recognises a current practitioner's outstanding contribution in eliminating trachoma.

Correspondence to Michael MacCallan, 15 Queen's Gate Gardens, London SW7 5LY, UK;

mmaccallan@yahoo.co.uk
Sir Ernest Cassel became so shocked at the extent of ophthalmia among the vast workforce $^{\text {iii }}$ that, in 1902, he established a trust fund of $£ \mathrm{E} 40000$ (equivalent to $£ 4$ million today) with the objective of teaching 'the principles of ophthalmic surgery to Egyptian surgeons'. The trustees decided to establish a first, experimental, travelling ophthalmic hospital (TOH) as had been used successfully in Russia. In 1903, Arthur, aged 31 years, was working as an unpaid ophthalmic surgeon at Moorfields. By a stroke of good fortune, which 'transcended even my dreams', he was offered the position in Egypt to operate that $\mathrm{TOH}$ and teach the Egyptian doctors the appropriate surgical skills.

Arthur arrived in Cairo in July 1903. $\mathrm{He}$ rapidly concluded that hospital doctors had little knowledge of eye treatment but that success of the TOH scheme would be assured, given the potential overwhelming demand for treatment. The first TOH, at Menouf, was opened to patients in January 1904 (figure 2). Initially, some of the fellabeen were suspicious of Arthur's motives. However, these prejudices were soon overcome by the empathy, skill and professionalism, by which Arthur organised and treated his patients; they could literally 'see' the benefits of his operations. Demand for treatment grew rapidly thereafter.

Arthur's volume of work was enormous. During the first 3 months of 1904 , at Menouf, he treated 6157 patients and performed 615 operations. Where anaesthetics were required, opium, cocaine or chloroform were used; in some cases, where no anaesthetics were available, patients might still insist on treatment so great was their desire for sight. This was also the era before antibiotics. Working conditions were harsh with the heat, sand, flies, lice and 'mosquitoes as big as sparrows, very bony and strong'. This combination of work and the environment put great strain on Arthur personally and he

${ }^{i i i}$ At that time, it was estimated that some 90\% of the population suffered from ophthalmia, with many operations being performed by 'quacks'. admitted that 'the work is now very onerous' and 'I don't know how long I shall be able to stand this sort of life'. Nevertheless, he persevered, recognising the overwhelming need by the population for professional treatment. Indeed, so successful were the results from the first $\mathrm{TOH}$ that, in 1904, Cassel provided the funds for a second one, initially established at Fayoum.

The high incidence of ophthalmia led Arthur to conclude that the availability of treatment at that time was just 'a drop in the ocean' even with the second TOH. Thus, a bolder, long-term plan was needed. To address this, Arthur planned to 'create a stable central ophthalmic administration with the best possible clinical and scientific teaching adjuncts', along with establishing a permanent ophthalmic hospital in each of Egypt's 14 provinces. Over the next 20 years, Arthur worked tirelessly to achieve his self-imposed goals.

Arthur is probably best known among the international ophthalmic profession for his research into and 'classification of the stages of trachoma'. His initial findings were published in 1908 and then further developed in his books Trachoma and its Complications in Egypt (1913) and Trachoma (1936). In 1952, the WHO adopted MacCallan's Classification as the standard. He was also instrumental in founding the major ophthalmic research establishment at Giza, then known as the Memorial Ophthalmic Laboratory, ${ }^{\text {iv }}$ which was formally opened in 1926 (figure 3) and which is still operational today. Arthur stated that 'this laboratory was envisaged by me many years beforehand. I got the site, the money for the building, arranged the endowment, and designed the interior, with all detail'. $\mathrm{He}$ believed that this Laboratory was 'the coping stone of my work'.

However, in order to treat the numerous patients with trachoma and other eye diseases, funding was required. To undertake this successfully, Arthur recognised that it was essential to involve the government in plans to create and develop an ophthalmic hospital infrastructure. This was achieved when, in 1905, the Egyptian Government took over the administration of the Cassel Fund and started providing funding. Arthur was delighted and noted that 'the national importance of the

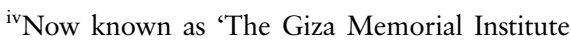
for Ophthalmic Research'. 


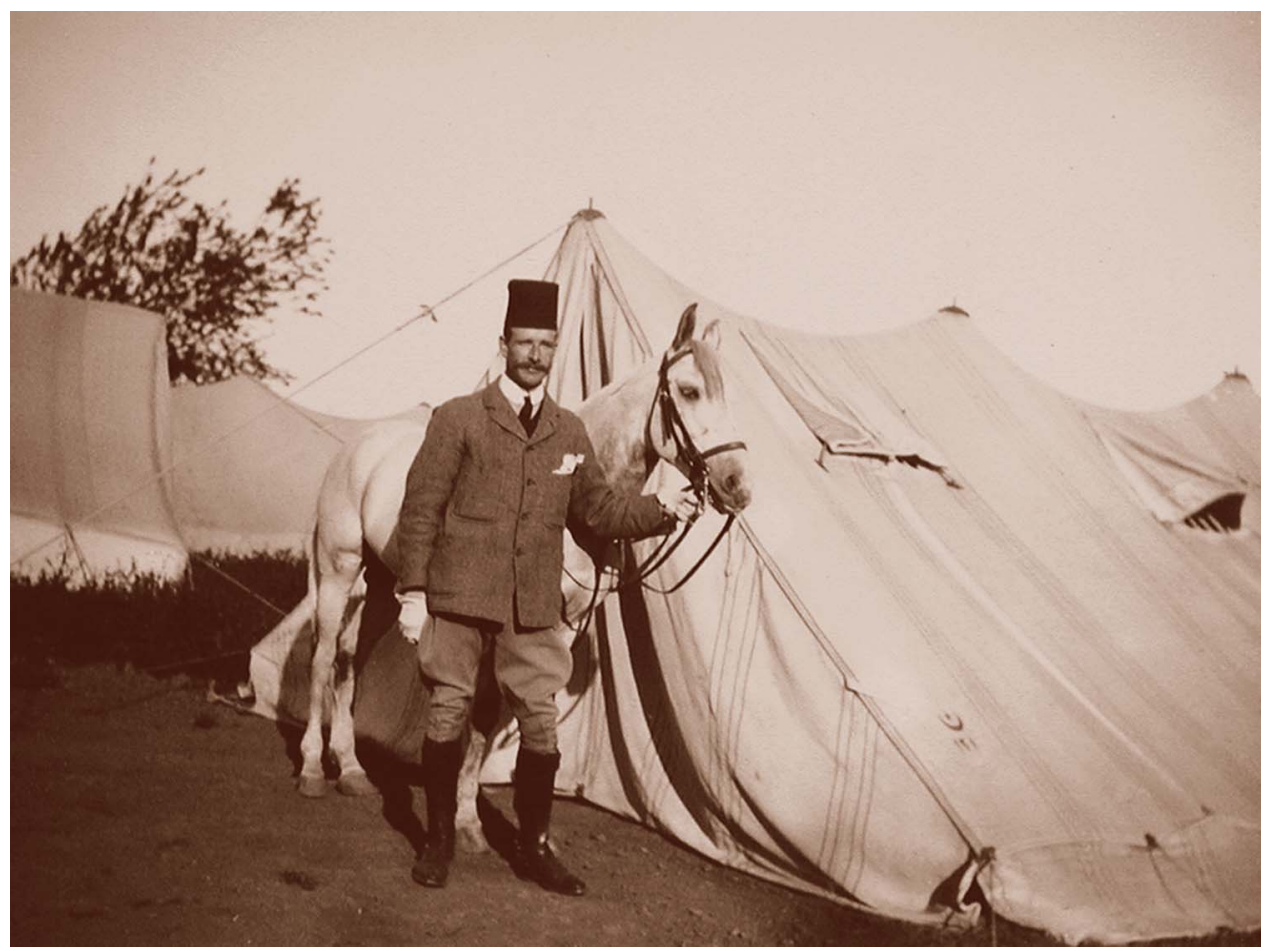

Figure 1 Arthur, the Pioneer, Menouf Camp, 1904, with Saladin.

struggle against ophthalmia has thus been recognised and must henceforth take its place amongst the measures essential to the prosperity of the country'. The first permanent ophthalmic hospital was opened at Tanta (1908); further hospitals were constructed over the years funded by a combination of local and government finance and, in many cases, generous donations of land and money from wealthy individuals.

The TOHs continued to play a vital role in treating patients around the country. In 1904, for example, the two TOHs treated patients at Menouf, Fayoum, Damietta and Calioub. Their mobility, and the effective treatment received by patients, led to the TOHs being a powerful 'roving advertisement' for the essential work being done, resulting in significant donations from the public. Given the flexibility of the TOHs, these 'hospitals under canvas' were used to great effect in 1915, during World War I, when they were commissioned by the military to treat the sick and wounded from the campaigns at the Suez Canal, Gallipoli and Salonica. The largest tent

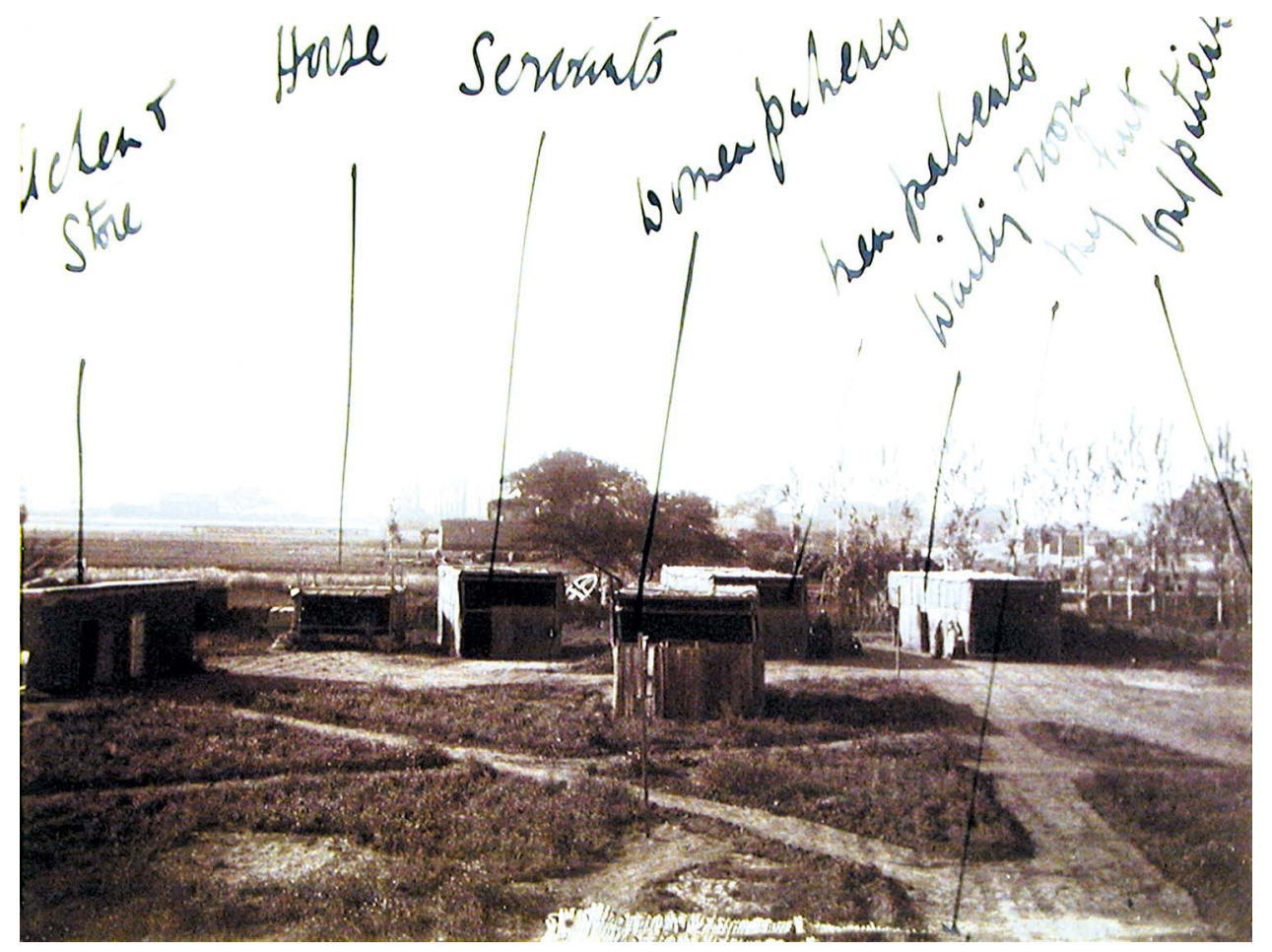

Figure 2 Mat huts at Menouf. These replaced canvas tents in summer. 


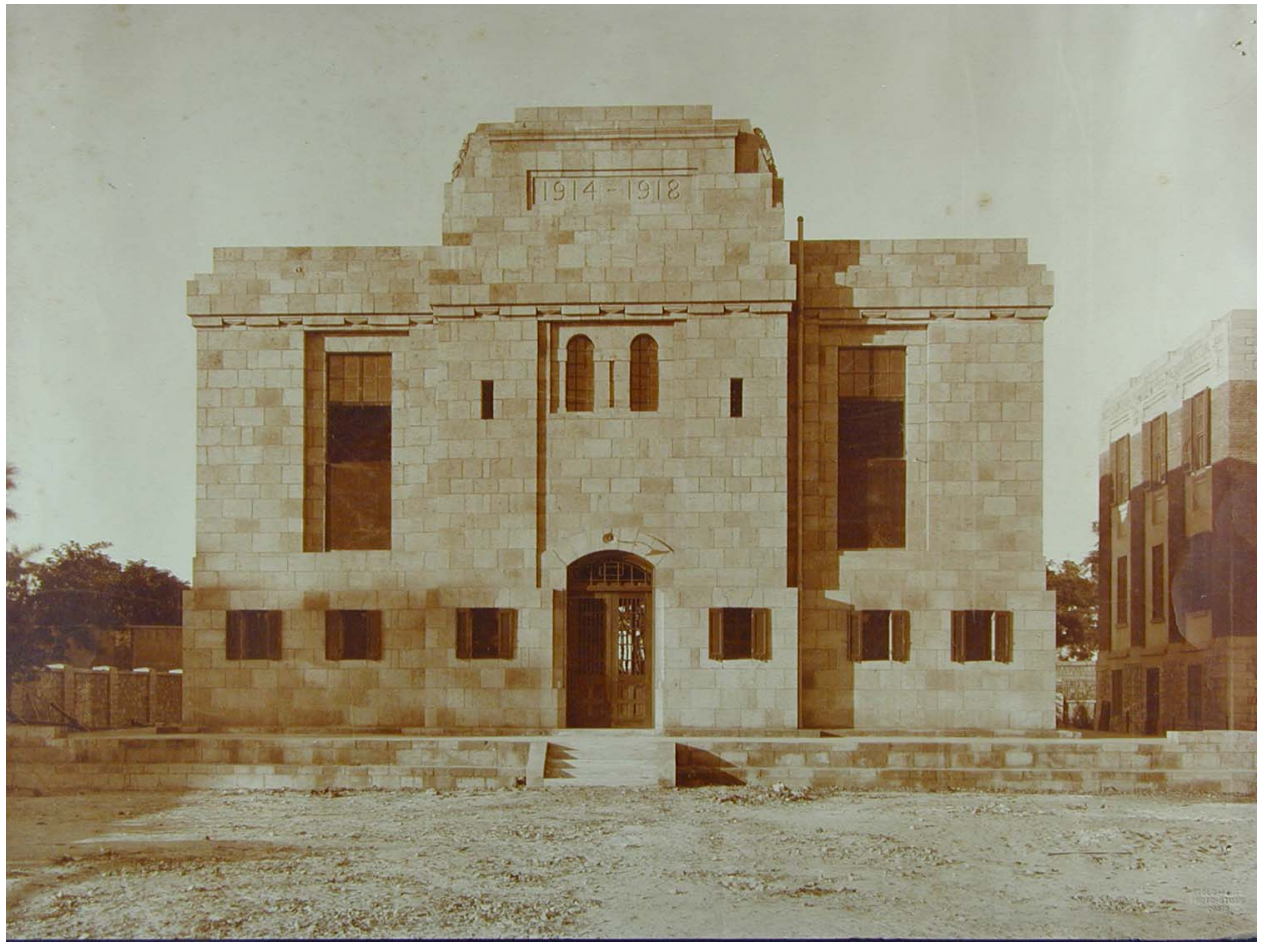

Figure 3 Memorial Ophthalmic Laboratory, Giza, 1925.

camp contained 650 beds; this was initially established in Alexandria and then moved to Giza for the winter of 1915. Arthur was commended by Surgeon-General Ford that his hospital was 'a model of what a war hospital under canvas should be'.

Two other areas addressed by Arthur were also essential to the successful achievement of his goals. First, he organised the training of ophthalmic surgeons to staff the hospitals; by 1923, the members of the Egyptian Ophthalmological Society had increased from 17 to 96. Second, Arthur believed that 'the most important work carried out was the institution of ophthalmic treatment in all Government Primary Schools throughout Egypt'. Given that trachoma was highly contagious, particularly in the close environment of the family unit or schools, Arthur dedicated much effort in educating people on the benefits of personal ophthalmic hygiene $^{\mathrm{v}}$ and so prevent the spread of the disease. Indeed, one of his first professional calls in 1903 was to the headmaster of Menouf School with the offer of inspecting the pupils for ophthalmia and offering appropriate treatment.

The tangible results of Arthur's efforts over 20 years led to a significant growth in the number of patients treated (3397 to

${ }^{\mathrm{v}}$ This emphasis on hygiene (clean hands, faces and towels) continues today as part of the WHO-endorsed SAFE strategy ('F'-facial cleanliness).
133 750: $40 \times)$, and operations performed, (1268 to 76035 : 60×). On Arthur's departure in 1923, there were 23 operational ophthalmic hospital units, including five TOHs and two planned hospitals. As important, however, was the fact that Arthur established robust foundations for the ophthalmic hospital infrastructure to develop after his departure. By 1937, there were 63 permanent ophthalmic hospitals, 15 travelling hospitals and treatment centres in 38 government schools. Many of these hospitals are operational today with the Fayoum ophthalmic hospital celebrating its centenary in 2015 .

Arthur bore the mantle of ambassador in promoting and ensuring the implementation of his self-imposed goals. Over the years, he persuaded both the government and local notables to provide significant funding and other support for the development of the ophthalmic hospital infrastructure. Arthur successfully achieved his goals while recognising that much still remained to be done. In 1931, Arthur's colleagues from the Egyptian ophthalmic service dedicated a commemorative bust to honour his illustrious career and accomplishments; this may still be seen today at the Giza Memorial Institute for Ophthalmic Research. It is touching to note that, when the bronze bust was imported into Egypt in 1930, the Ministry of Finance agreed to waive the customs duty in recognition of the 'moral significance' of Arthur's work over 20 years. This sentiment remains to this day, as witnessed by the 'ICTC MacCallan Medal'. Arthur's pioneering spirit continues to inspire, and resonate with, today's profession as they continue the fight to eliminate blinding trachoma.

\section{Competing interests None.}

Provenance and peer review Commissioned; internally peer reviewed.

\section{(1) \\ OPEN ACCESS}

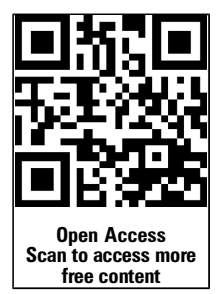

Open Access This is an Open Access article distributed in accordance with the Creative Commons Attribution Non Commercial (CC BY-NC 4.0) license, which permits others to distribute, remix, adapt, build upon this work non-commercially, and license their derivative works on different terms, provided the original work is properly cited and the use is noncommercial. See: http://creativecommons.org/licenses/ by-nc/4.0/

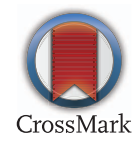

To cite MacCallan M. Br J Ophthalmol 2015;99:577579.

Published Online First 26 March 2015

Br J Ophthalmol 2015;99:577-579.

doi:10.1136/bjophthalmol-2014-306527 


\section{Correction}

MacCallan M. Arthur Ferguson MacCallan: trachoma pioneer in Egypt 1903-1923. Br J Ophthalmol 2015;99:577-9. The Provenance and peer review statement should read: Commissioned; externally peer reviewed.

Br J Ophthalmol 2015;99:1154. doi:10.1136/bjophthalmol-2014-306527corr1 